\title{
ORIENTAÇÃO EDUCACIONAL: O COMBATE À EVASÃO ESCOLAR NA PANDEMIA
}

\author{
Daiane Rodrigues Gago ${ }^{1}$ \\ Silvana Corbellini ${ }^{2}$
}

\begin{abstract}
RESUMO
O presente trabalho trata-se de uma pesquisa qualitativa com orientadores educacionais da rede estadual de ensino do Rio Grande do Sul sobre o seu papel no combate à evasão escolar com foco no período após o início da pandemia pelo COVID-19. Através desse estudo, procuramos conhecer a praxe laboral desse profissional e entender como se dá a sua atuação para combater a evasão, não somente após a pandemia, como também em sua realidade anterior a ela, e ainda, suas perspectivas para o período pós pandemia. Mesmo em um quadro totalmente novo e incerto em relação ao futuro, devido o início da pandemia, percebemos o quanto esses profissionais foram capazes de se adaptar, através da apropriação do uso das tecnologias, ainda que não o fizessem antes desse período, e superar seus próprios anseios e incertezas afim de um bem maior que é o de oportunizar a melhor qualidade de atendimento possível para seus estudantes e comunidade escolar.
\end{abstract}

Palavras-chave: Evasão Escolar; Orientador Educacional; Pandemia.

EDUCATIONAL ADVISOR: THE COMBAT A SCHOLAR EVASION IN THE PANDEMIC

\begin{abstract}
The present work is a qualitative research with educational advisors from the state educational system about their role in combating school dro pout, focusing on the period after the beginning of the COVID-19 pandemic. Through this study, we aim at knowing the practice of these professionals and understand how they act to fight school evasion, not only after the pandemic, but also in their reality prior to it, as well as their perspectives for the post-pandemic period. Even in a completely new and uncertain situation regarding the future, due to the onset of the pandemic, we will see how these professionals were able to adapt, through technology appropriation, even as something new to them, and overcome their own desires and uncertainties in order to achieve a greater good, which is to provide the best service and care for their students and the school community.
\end{abstract}

Key worlds: Scholar evasion; School Advisor; Pandemic.

\footnotetext{
${ }^{1}$ Bacharel em Letras (Língua Portuguesa) pela Universidade Federal do Rio Grande.

2 Professora adjunta da área da Psicologia da Educação do Departamento de Estudos Básicos da Faculdade de Educação da Universidade Federal do Rio Grande do Sul. Email: silvanacorbellini@gmail.com Orcid: https://orcid.org/0000-0002-3335-0387
} 


\section{INTRODUÇÃO}

O presente trabalho visa conhecer a rotina laboral do Orientador Educacional $(\mathrm{OE}) \mathrm{com}$ foco no combate à evasão escolar, bem como as alterações sofridas por essa prática em função da pandemia pelo Covid-19. Sabemos que o trabalho do orientador é bastante amplo e vai além das questões relativas à evasão, dessa forma, faremos um apanhado geral para compreendermos, de maneira mais ampla, em que implica o seu trabalho, sem deixar de nos aprofundarmos no principal objetivo, que é entender como essa figura age para diminuir os índices de alunos evadidos e por quais adaptações precisaram passar em razão da pandemia.

Quando se fala em evasão, é difícil deixar de fora o termo “abandono escolar", veremos a seguir o que tem de diferente entre esses dois termos e também como essa diferença pode ser sutil e confundir até mesmo quem trabalha com educação. Porém, ressaltamos aqui que o foco da pesquisa é o combate à evasão, não desconsiderando a importância de um aluno que abandona a escola, mas considerando que esse abandono é o primeiro passo ao caminho da evasão. Então, subentende-se que qualquer atuação realizada com um aluno que esteja em situação de abandono, contribui para evitar a evasão.

A pandemia - causada pelo Covid-19 - gerou, e ainda está gerando, grandes impactos que estão sendo sentidos por toda a população em todos os setores, e na educação não seria diferente. Trabalhadores em educação tiveram suas rotinas totalmente modificadas pelo novo, incerto e desconhecido, precisando se adaptar dia após dia para cumprirem o seu papel em um cenário inédito, da melhor maneira possível. E nesse contexto, encontra-se também o orientador educacional, que comumente tem contato direto com os discentes, precisando nesse período utilizar de uma reinvenção para conseguir manter esse vínculo e agir contra à evasão.

Dentro desse contexto veremos que o uso das tecnologias, mesmo já sendo feito pela maioria dos profissionais, fez-se essencial para a realização do trabalho dos orientadores. Fazendo com que até mesmo aqueles mais resistentes, cedessem a sua utilização. Para tanto, no trabalho investigou-se o papel do Orientador Educacional; a evasão escolar e o uso das tecnologias no trabalho da evasão do Orientador Escolar.

A metodologia utilizada foi pesquisa qualitativa realizada através do Estudo de Caso, a qual será compreendida através da Análise de Conteúdo (BARDIN, 1977). Para a coleta de dados realizou-se um questionário online, que foi respondido por quatro orientadores, com questões relativas as suas práticas, respeitando o foco na evasão e nas alterações sofridas pela pandemia, 
que compuseram categorias a priori. Dessa forma, poderemos analisar a rotina desses profissionais, que aceitaram colaborar com a pesquisa, juntamente com a perspectiva de alguns autores estudados ao longo do curso para que possamos dar embasamento aos nossos estudos.

Acreditamos que dessa forma, o presente trabalho contribua para entendermos o compromisso que o orientador educacional tem dentro da sua profissão e como essa figura pode agir para que a evasão escolar se torne cada vez menor. Além de contribuir para percebermos a importância do uso das tecnologias como um aliado para o êxito das suas funções, uma vez que até mesmo os mais resistentes, tecnologicamente falando, tiveram que se render ao mundo virtual.

\section{REFERENCIAL TEÓRICO}

\subsection{CONHECENDO O TRABALHO DO OE}

Compreender os deveres de um orientador educacional é parte fundamental no entendimento de seu trabalho afim de não o confundirmos com demais trabalhadores da educação. Sobre isso, David (2017, p. 106), em seu artigo "O orientador educacional e a escola: a criação de espaços de participação social e exercício da cidadania”, coloca:

A função do Orientador Educacional não deve ser confundida com a função do supervisor escolar ou com a função do psicopedagogo escolar, pois são funções diferentes, mas cada um desses profissionais dando o seu apoio para a educação e para o desenvolvimento escolar do aluno. O Orientador Educacional usará do diálogo no seu ambiente de trabalho, na organização escolar, também irá intermediar conflitos escolares, auxiliar o corpo docente em relação às dificuldades de aprendizagem escolar, quando houver casos que necessitam de intervenção e de ajuda.

Ainda pensando no entender das atribuições do orientador educacional, é muito comum atribuir a esse profissional o título daquele que atende ou resolve os "problemas", vinculando a sua rotina à resolução de conflitos com e entre os alunos. Sobre isso, Lück (2000, p. 2) coloca:

[...] o que se observa, muitas vezes, no ambiente escolar é que: [...] não tão raramente, gestores e profissionais em geral que se lamentam de estarem trabalhando como quem está "apagando incêndios", isto é, de estarem "sempre correndo atrás do prejuízo" e sendo conduzidos pelas situações variadas do cotidiano, pelas demandas inesperadas, tendo que responder rapidamente a elas e de tal forma que "não têm tempo para pensar, quanto menos para planejar. 
Precisamos entender a dinâmica do seu trabalho como um todo e perceber que o seu papel vai muito além do que simplesmente "apagar incêndios", para isso, a autora Grinspun (1994) aponta para a necessidade de uma abordagem com foco na formação de cidadão em consonância com o seu tempo e espaço.

Ainda sobre o papel do orientador, podemos considerar o que diz Noal (2004, p. 14): "Ser orientador é uma opção, mas atuar como orientador significa enfrentar constantes desafios, buscando atitudes cotidianas que promovam a união e integração".

E refletindo sobre esse desenvolvimento do processo de cidadania citado por Grinspun (1994), e na promoção da união e integração entre os sujeitos, trazida por Noal (2004), podemos compreender que para o êxito de seus deveres, o orientador precisa conquistar o aluno, é preciso estabelecer um vínculo, principalmente de confiança entre ambos. É através desse elo que o discente de sentirá à vontade para recorrer ao orientador e também, de ser atendido por ele em momentos de conflito, é a ligação e a confiança que garantirão o sucesso no desempenho das funções desse profissional.

Sobre isso, a autora Kupfer (1989) traz em sua obra que Freud afirma que o educador é aquele que deve buscar, para seu educando, o justo equilíbrio entre o prazer individual e as necessidades sociais. Afirma ainda, que um professor pode ser ouvido quando está revestido, por seu aluno, de uma importância especial. Daí se dá a essencialidade do elo entre orientador e aluno, embora nas palavras de Freud esteja citada a figura do professor, o mesmo se estende ao orientador.

\subsection{COMPREENDENDO EVASÃO ESCOLAR}

Que educação é um direito universal, todos nós sabemos. Sabemos também, conforme consta no Estatuto da Criança e do Adolescente que:

Art. $4^{\circ}$ É dever da família, da comunidade, da sociedade em geral e do poder público assegurar, com absoluta prioridade, a efetivação dos direitos referentes à vida, à saúde, à alimentação, à educação, ao esporte, ao lazer, à profissionalização, à cultura, à dignidade, ao respeito, à liberdade e à convivência familiar e comunitária.

Então sabendo que as crianças e adolescentes têm direito à educação, que por sua vez é de responsabilidade da família, da comunidade, da sociedade em geral e do poder público, precisamos investigar o porquê a evasão escolar ainda é algo presente nas escolas e para isso, o princípio é 
compreendermos a evasão escolar para, posteriormente, analisarmos como o orientador pode trabalhar a fim de combater essa realidade.

Para essa compreensão, começaremos evidenciando uma diferença sutil, que confunde até mesmo quem trabalha na área da educação, a diferença de conceito entre evasão e abandono escolar. Não é incomum que esses dois termos sejam compreendidos como sinônimos e que até mesmo a sua definição por autores da área gerem questionamentos sobre tais diferenças. Sobre essa dificuldade de precisão na definição desses conceitos, os autores Raimundo Silva Filho e Ronaldo Araujo (2017, p. 37) já afirmavam que "suas várias formas de interpretação não permitem definir exatamente evasão e abandono escolar".

Concordando com isso, os autores Ivan Nadai e Franklin Santos (2018) expõem que não é uma tarefa simples conceituar esses termos, mas que é um consenso que em ambos os casos, tratase de alunos que, por motivos diversos, deixam as escolas, comprometendo seu futuro intelectual e social.

Para termos um norte então, em relação a essa diferença conceitual, ainda que pequena e que divide opiniões, consideremos aqui, o conceito abordado pelo INEP, Instituto Nacional de Estudos e Pesquisas Educacionais Anísio Teixeira, no qual a diferença está pautada no retorno do aluno; enquanto no abandono o aluno que deixou a escola retorna no ano seguinte, na evasão esse retorno não acontece. Sobre isso, e pensando que nossa pesquisa tem como foco trabalhar com o conceito de evasão, consideremos como a autora Thainá Anuto (2013) conceitua tal termo como:

A evasão escolar compreende, em linhas gerais, o abandono da escola durante o
período letivo, ou seja, o aluno se matricula, inicia suas atividades escolares,
porém, em seguida deixa de frequentar a escola, por uma ou um conjunto de
razões. Outra situação de evasão é quando o aluno se matricula, inicia o período
letivo, no entanto, desiste ou embrenha na fuga do estabelecimento de ensino.
Este seria na perspectiva mais adequada a evasão, cuja sanção seria a reprova por
falta. (...) A evasão, de forma clássica, consiste no ato ou processo de evadir, de
fugir, de escapar ou esquivar-se dos compromissos assumidos ou por vir a
assumir. Neste sentido, pode-se perceber que o termo evasão impõe uma marca
para caracterizar o fenômeno de fuga (p. 19).

A autora citada acima, ainda afirma em sua obra o fato de haverem não só fatores externos à escola, que vão interferir na vida escolar do aluno, contribuindo para essa evasão, mas também, fatores internos da escola, os quais impactam no seu processo-educacional, acabando por excluílo da escola seja por evasão ou por repetência.

Existem diversos fatores que podem contribuir para o aumento da evasão escolar, muitos, são externos à escola, como por exemplo carência de recursos financeiros. Pensando nessa questão econômica como agravante da evasão, Paro (1996) afirma: 
[...] a grande maioria da população de nossas escolas apresenta todos os tipos de problemas relacionados à desnutrição, fome, carência cultural e afetiva, falta de condições materiais e psicológicas para o estudo em casa, necessidade de trabalhar para ajudar no orçamento doméstico, bem como uma série de outros problemas, advindos do estado de injustiça social vigente e que comprometem o desenvolvimento do aluno na aprendizagem (p. 143).

O fator econômico envolve uma série de outras questões, como falta de incentivo por parte dos familiares, que ocupados demais com seus trabalhos acabam deixando os filhos autônomos no seu processo educativo, falta de estrutura no ambiente familiar para estudos extraclasse e até mesmo carência de recursos, que vão repercutir na eficiência e concentração por parte dos alunos na sala de aula. Além daqueles que já exercem suas próprias funções laborais e têm dificuldades em conciliar horários ou já chegam à escola cansados demais para serem participativos.

Ao encontro disso, Faria e Moura (2015, p. 153) traz a seguinte afirmação: “Ademais outros aspectos como a pressão que o trabalho exerce sobre as condições dos estudantes trabalhadores, o que implica em limitações para conciliar trabalho, escola e família, repercutem na desistência escolar".

Lorenzet e Zitkoski (2017, p. 464) observam que a permanência e o sucesso escolar dependem de diversas variáveis, relacionadas tanto à instituição que não corresponde às expectativas sociais e aos aspectos individuais do aluno e da sua família.

Na mesma linha, os autores Dore e Lüscher (2011) dizem:

A evasão escolar tem sido associada a situações tão diversas quanto a retenção e repetência do aluno na escola, a saída do aluno da instituição, a saída do aluno do sistema de ensino, a não conclusão de um determinado nível de ensino, o abandono da escola e posterior retorno. Refere-se ainda àqueles indivíduos que nunca ingressaram em um determinado nível de ensino, especialmente na educação compulsória, e ao estudante que concluiu um determinado nível de ensino, mas se comporta como um dropout (p. 775).

Seguindo, Rumberger (2011) também aponta para uma grande variedade de fatores, dentre eles aqueles relacionados à escola, família e trabalho, que podem contribuir para o fenômeno da evasão. Refere ainda, que a interação entre esses fatores, ao longo do tempo, dificulta que se consiga demonstrar uma relação causal entre um dos fatores isolados e a decisão de abandonar a escola. Já para Sales et al (2013, p. 6), a evasão escolar “é um fenômeno complexo, multifacetado e multicausal; está atrelado a fatores pessoais, sociais e institucionais."

Complementando essa ideia, Rumberger (2011) distingue dois tipos de fatores: os individuais, que são relacionados aos próprios estudantes, suas atitudes e comportamento, ao desempenho escolar e suas experiências prévias. Aqui entram a falta de motivação, absenteísmo, 
mau comportamento, gravidez e baixo desempenho escolar. E, os contextuais, que são associados às famílias, às escolas e às comunidades. Nesse item, em relação às famílias aponta a condição socioeconômica, escolaridade dos pais, estrutura familiar; às escolas destaca quatro características, a composição do corpo docente, características estruturais, recursos escolares e políticas e práticas; e às comunidades, salienta as diferenças de bairros, a influência dos grupos.

\subsection{O PAPEL DO OE NO COMBATE À EVASÃO ESCOLAR}

O orientador escolar é aquele profissional que está envolvido com toda escola e comunidade escolar. Trabalha desde a direção, passando pelo corpo docente, discente e familiares. Ele ainda pode ser visto pelos alunos como uma extensão do corpo docente, pois é nessa figura que o estudante encontrará amparo nas suas aflições dentro da escola. Lück (2002, p. 28) salienta que "[...] é o professor que forma no aluno o gosto ou o desgosto pela escola, a motivação ou não pelos estudos; a percepção de sua capacidade de aprender e de seu valor como pessoa". E, pensando no orientador como uma extensão do professor, é também ele que pode gerar no aluno esse gosto pela escola, quanto mais estimulado e entusiasmado o aluno estiver em relação à escola, mais distante estará da evasão escolar.

Como aponta Corbellini (2020):

Em tempos de pandemia, em que a população se encontra em sofrimento psíquico, vulnerável, ater-se aos conteúdos pode ser um não senso. Hoje, precisamos auxiliar aos nossos estudantes a adquirirem condições de compreensão do mundo, das relações e de lidar com o que está ao seu redor. (p. $67)$.

Ao encontro do que traz Corbellini, pensando que o estudante precisa ter condições de lidar com o que está ao seu redor e visando a diminuição do índice de evasão escolar, pensemos no que Lück (2008, p. 07) afirma sobre o clima emocional do ambiente escolar e suas consequências:

O clima emocional de trabalho, o estabelecimento de prioridades de ação, o tipo de relacionamento professores-professores, professores-alunos, escolacomunidade, dentre outros aspectos importantes da vida escolar, dependem, sobremaneira, da atuação dos elementos que ocupam aquelas posições.

Assim, o papel do Orientador Educacional mostra-se essencial no contexto escolar para que o mesmo possa mediar as situações necessárias com todos os envolvidos no processo educativo, garantindo o êxito das relações entre os mesmos, o que repercutirá em um ambiente 
emocionalmente saudável e receptivo aos seus discentes, dessa forma, consequentemente, contribuindo para a diminuição do número de alunos evadidos. De acordo com Pascoal et al (2008), o orientador educacional deve ser mediador entre o aluno e as situações de caráter didáticopedagógico e as situações socioculturais.

Ainda contribuindo sobre a prática do orientador educacional e seus efeitos na diminuição da evasão, Lück (2008) acrescenta:

Uma ação educativa relevante e um currículo positivo unem em uma associação harmoniosa os conhecimentos, habilidades e sentimentos. Consideram equilibradamente tanto as necessidades individuais como as de grupo, as pessoais e as institucionais. A educação sob esse ângulo traduz o ponto de vista da orientação educacional (p. 19).

Seguindo na mesma perspectiva e colaborando para ideia de que o orientador pode fomentar no aluno o gosto pela escola e a consciência da necessidade dos estudos, estimulando-o a vencer as limitações que possam dificultar a sua assiduidade e permanência na escola, Piaget (1998) também afirma que a criança é um sujeito ativo e que a razão é construída a partir da vida em grupo, que é um componente natural para a atividade intelectual e para a cooperação.

Na mesma linha, Corbellini (2012) refere que:

A educação dessa maneira configura-se de uma forma ampla, indissociável e não temos como formar sujeitos autônomos, tratando-os coercitivamente. Ressalta Piaget (1973) que quando o sujeito é passivo intelectualmente, será também moralmente e que a recíproca é verdadeira: se o sujeito é moralmente submisso à vontade do outro, será também intelectualmente. Ou seja, não terá condições de emancipar-se, pois, tenderá a ficar submetido, passivo ao desejo do outro (p. 8).

Assim, para refletir sobre o papel do Orientador Educacional torna-se imprescindível compreender quais as suas funções. De acordo com Lorenzet e Zitkoski (2017) o OE tem um papel mediador, envolvido nas dimensões filosóficas, sociais, políticas, pedagógicas e a sua contribuição é imprescindível para as aprendizagens significativas e para o desenvolvimento integral dos estudantes.

Que o orientador educacional assume o papel de mediador entre os sujeitos envolvidos do processo educativo, vários autores, conforme citações acima, concordam; mas não podemos esquecer o grande foco dessa ação pedagógica, que é e sempre deve ser o aluno, sobre isso, Elenilda Silva e Aristófanes da Silva (2015) trazem em seu artigo "Orientação Educacional: desafios da contemporaneidade": 
Na visão contemporânea da orientação educacional o aluno é o centro da ação pedagógica, cabendo ao orientador atender a todos os alunos em suas solicitações e expectativas. Assim, o profissional de orientação educacional torna-se um mediador entre o aluno e o meio social, pois promove discussões sobre os problemas e assuntos da atualidade, principalmente os que fazem parte do contexto sociopolítico, econômico e cultural em que vivemos. (p. 2).

E é através dessa perspectiva que o orientador vai conseguir trabalhar no combate à evasão escolar, seu trabalho é preventivo, ele deve estimular no aluno o gosto pelo conhecimento e a consciência pela necessidade dos estudos para seu pleno desenvolvimento social e crítico. Os mesmos autores, Elenilda Silva e Aristófanes da Silva (2015, p. 7), ainda no referido artigo, já afirmavam que a escola conta com o orientador para colaborar com os alunos frente às suas necessidades, preocupando-se com sua formação pessoal e desenvolvendo propostas que elevem o seu nível cultural, tudo para que o ambiente escolar seja o melhor possível. Situação que vai ao encontro do combate à evasão escolar, quanto mais as práticas do orientador forem voltadas à qualidade do ambiente escolar ofertado ao aluno, mais motivado ele estará e, consequentemente, mais distante da possibilidade de abandonar os estudos.

\subsection{O USO DAS TECNOLOGIAS NO TRABALHO DA EVASÃO DO OE}

Para começarmos a falar em tecnologia na educação, vamos retroceder um pouco e pensar como era essa educação antes do surgimento de tal recurso, sobre isso, consideremos o que as autoras Vera Lúcia da Silva e Lúcia Amante (2015) colocam em seu artigo “Objectos da Escola? Quando novos personagens entram em cena":

Na virada do século XIX para o XX, os professores recebiam formação para trabalhar com ferramentas que lhes eram familiares: ao entrar em sala, de fato tinham maior destreza no manuseio das tecnologias escolares que os alunos: $o$ quadro negro, os cadernos etc. Colocados muitas vezes como modelo, serviam de referência e inspiração na construção de modos de viver em sociedade, cujo "ideal" era esculpido pela instituição escolar (p. 3).

Porém, o tempo passou e a evolução aconteceu. Com isso, é normal que alguns educadores se sintam inseguros e até mesmo ameaçados pela tecnologia. O uso das tecnologias, principalmente a internet, vem se popularizando cada vez mais, o que não é indiferente à rotina laboral das escolas, que por sua vez, inclui o orientador educacional, sobre isso, Lopes (2012) comenta: 
A Internet vem se popularizando a cada dia que passa. Num intervalo de apenas dez anos, a rede mundial deixou de funcionar apenas como suporte para a transmissão de dados entre computadores para se tornar um recurso multimidiático para a comunicação entre pessoas e instituições públicas e privadas. Para dar conta do volume de usuários, a Internet se transformou numa megaestrutura através da qual circulam informações digitalizadas de diversos teores - ideias, conceitos, projetos, arte, problemas sociais, entretenimento, soluções, comércio, etc. - e formas - textos e hipertextos, fotos, áudio, vídeo, infográficos, etc. (p. 206).

Em relação a essa popularização e inserção das tecnologias no ambiente escolar, cabe aos trabalhadores da educação apropriarem-se dessa utilização para potencializar os resultados do seu trabalho, sobre isso os autores Anderson Nascimento e Kelley Gasque (2017, p. 206) trazem em seu artigo "Novas Tecnologias, a busca e o uso de informação no Ensino Médio" que "o uso adequado das novas tecnologias, a capacidade de pesquisar e de buscar informação possibilitam que os indivíduos saibam lidar com a informação para tomar decisões e resolver problemas", dessa forma, a utilização dos recursos tecnológicos guiada pelos educadores - o que inclui os orientadores - só tem a contribuir positivamente no aumento da qualidade do processo educativo, o que tem relação direta com a diminuição da evasão.

Além dessa popularização ser um processo natural, podemos dizer também que a pandemia pelo COVID-19 pode, de certa forma, ter potencializado essa utilização dos recursos tecnológicos. Mesmo aqueles profissionais que se mostravam mais resistentes às tecnologias, com o início da pandemia, acabaram não tendo muita escolha a não ser se renderem a ela. O trabalho do orientador, que requer um contato direto com os alunos, se viu totalmente modificado pelo distanciamento social; de modo que a tecnologia, através da internet e também do uso de redes sociais, viabilizou a manutenção desse contato, ainda que apenas de modo virtual.

Dessa forma, podemos constatar que a tecnologia possibilita o contato entre orientadores e discentes, de modo que se mantenha o vínculo entre ambos para que esse profissional possa exercer suas funções, incluindo a do combate à evasão escolar.

Da mesma forma, Corbellini (2012) contribui:

Observamos que as possibilidades de termos acesso às tecnologias, como instrumentos na educação, podem auxiliar-nos a modificarmos a forma de pensar e de agir. A partir de um uso cooperativo, ou seja, incluindo-se a cooperação no âmbito educacional, podemos principiar a esboçar novos contornos. [...] A socialização imposta pela democratização do conhecimento via tecnologia expõe os sujeitos em seus saberes e ignorâncias. Desta forma, este confronto com o fato de que não se sabe tudo e, aliando-se ao saber que a rede oferece, podemos trabalhar cooperativamente na construção de novos conhecimentos (p. 9). 
Na mesma linha, evidenciando as possibilidades trazidas pela utilização da tecnologia, André Lemos (2006) traz em seu artigo "Cibercultura como território Recombinante":

As novas tecnologias de comunicação e informação serão vetores de agregação social, de vínculo comunicacional e de recombinações de informações as mais diversas sobre formatos variados, podendo ser textos, imagens fixas e animadas e sons. A cultura "pós-massiva" das redes, em expansão com sites, blogs, redes de relacionamento como o Orkut, troca de fotos, vídeos e música em sistemas como Flickr, YouTube e redes P2P, mostra muito bem o movimento de recombinação cultural em um território eletrônico em crescimento planetário. (p. 38 - 39).

Ao encontro dessas informações sobre as potencialidades oriundas do uso de recursos tecnológicos, as autoras Silva e Amante (2015, p. 8), no artigo já citado, também abordam que as tecnologias digitais são formas de representação do mundo contemporâneo. Alegando que se tratam de ferramentas culturais, sociais e cognitivas, defendendo a ideia de que a sua utilização determina novas formas de entender, distribuir e construir o conhecimento. O que, mais uma vez, aumenta a qualidade ofertada pela escola, diminuindo assim os números da evasão.

\section{METODOLOGIA}

Esse trabalho trata-se de uma pesquisa qualitativa que foi realizada através de um estudo de caso. Como instrumentos de coleta de dados utilizou-se um questionário com quatro orientadoras educacionais que atuavam em escolas públicas da rede estadual do estado do Rio Grande do Sul.

Em um levantamento feito no site da $18^{\circ} \mathrm{CRE}$, verificou-se que das mais de trinta instituições públicas da rede estadual, apenas treze delas atendem o público do ensino médio. Dentre elas, algumas não contam com a figura do orientador educacional, por falta de pessoal ou por afastamento médico do mesmo. Entre as escolas que possuem orientação educacional no ensino médio, conseguiu-se a participação de quatro profissionais que responderam o questionário.

O tema da pesquisa é o trabalho do orientador educacional no combate à evasão escolar em tempos de pandemia. Dessa forma, nosso objetivo geral é investigar como o trabalho do orientador educacional pode contribuir para diminuir a evasão escolar em tempos de pandemia. E para isso, temos como objetivos específicos: compreender a evasão escolar e o papel da orientação educacional; conhecer a rotina do orientador educacional das escolas estaduais de ensino médio 
de Rio Grande; elencar práticas do orientador educacional em sua rotina normal de trabalho, antes e após o início da pandemia e investigar como a pandemia alterou a forma dos orientadores educacionais utilizarem a tecnologia na sua praxe.

Para a análise dos dados foi considerada a Análise de Conteúdo (AC) de Bardin (1977), a qual é bastante utilizada nesse tipo de pesquisa.

A partir do referencial teórico já se elaborou duas categorias a priori de acordo com o interesse da pesquisadora e outras duas surgiram a posteriori a partir da análise dos dados. As quatro categorias serão apresentadas e analisadas a seguir.

\section{APRESENTAÇÃO E ANÁLISE DE DADOS}

Contamos com a participação de quatro orientadoras educacionais que se dispuseram a colaborar com a pesquisa, todas atuantes em escolas públicas estaduais de Rio Grande. A fim de preservar a identidade de todas, nomearemos ficticiamente as quatro participantes como PA, PB, $\mathrm{PC}$ e PD. As participantes $\mathrm{PA}, \mathrm{PB}$ e $\mathrm{PC}$ responderam o questionário por escrito, enquanto a participante PD respondeu através de áudios via Whatsapp, os quais foram posteriormente transcritos pela pesquisadora.

O questionário conta com um cabeçalho de caracterização das participantes e um total de nove questões, das quais somente PD não respondeu a todas, limitando-se a responder as questões 1, 2, 3, 5 e 7. Como no Termo de Livre Consentimento, consta que a colaboração com a pesquisa pode ser interrompida a qualquer momento, foi respeitada as respostas da orientadora.

Primeiramente, iremos apresentar a caracterização dos sujeitos, que será feita no próximo item. A seguir, a interpretação da coleta de dados feita nas nove questões será apresentada através de quatro categorias, sendo elas: O papel do Orientador Educacional no combate à evasão escolar; Principais desafios enfrentados pelo Orientador Educacional para eficácia da sua prática no combate à evasão; Uso das tecnologias por parte do Orientador Educacional; e, Expectativas para o período pós pandemia - sendo as três primeiras, divididas em duas subcategorias cada: Período anterior à pandemia e Período posterior ao início da pandemia. 


\subsection{Caracterização dos Sujeitos}

Participaram dessa pesquisa quatro Orientadoras Educacionais. As participantes serão representadas através das nomenclaturas PA, PB, PC e PD e podemos, através do Quadro 1, visualizar suas idades, tempo de atuação na função de orientadora educacional, etapa de ensino em que atuam na rede pública estadual e também, o grau de formação acadêmica de cada uma delas.

Quadro 1 - caracterização das participantes

\begin{tabular}{|l|l|l|l|l|}
\hline & \multicolumn{1}{|c|}{ Idade } & $\begin{array}{c}\text { Tempo de atuação } \\
\text { na OE }\end{array}$ & \multicolumn{1}{|c|}{$\begin{array}{c}\text { Etapa de Ensino na Rede } \\
\text { Pública Estadual }\end{array}$} & \multicolumn{1}{|c|}{ Formação Acadêmica } \\
\hline PA & 55 anos & 3 anos & Ensino Fundamental & Mestrado \\
\hline PB & 59 anos & 26 anos & Ensino Médio & Especialização \\
\hline PC & 62 anos & 26 anos & Ensino Médio & Especialização \\
\hline PD & 61 anos & 25 anos & Ensino Médio & Especialização \\
\hline
\end{tabular}

Fonte: As autoras

\subsection{CATEGORIAS}

\subsubsection{Categoria 1: $\mathrm{O}$ papel do $\mathrm{OE}$ no combate à evasão escolar}

A primeira categoria, que foi estabelecida a priori, visa entendermos qual o papel exercido por esse profissional a fim de combater à evasão escolar. De modo que, dividimos a categoria em duas subcategorias, pois, não podemos desconsiderar as alterações sofridas na prática desse sujeito a partir do período em que se iniciou a pandemia pelo COVID-19. Com isso, buscou-se conhecer sua praxe convencional e as adaptações que foram necessárias com o surgimento da pandemia.

\subsubsection{Subcategoria: Período anterior à pandemia}

O objetivo aqui é conhecer o papel do orientador educacional, anterior à pandemia, no contexto escolar, focando o combate à evasão. Sobre esse item, é consenso entre todas que o papel do orientador escolar está consolidado em valores empáticos, é através da acolhida e do diálogo que é baseada a relação entre estudante e orientador, afim de que a partir disso se possa dialogar, orientar e incentivar o discente a investir em seus estudos e consequentemente, em seu futuro.

Esses dados são exemplificados nos relatos a seguir, nos quais as orientadoras referem-se as suas práticas anteriores ao Covid-19: PA diz: Acredito que o fazer do orientador educacional é perpassado por várias ações: observar, ouvir, perguntar, aconselhar, mediar, solidarizar-se, compreender, proteger, influenciar, resgatar, articular, cultivar, emocionar, espalhar sementes 
de empatia. PB refere que: $O$ fazer pedagógico da Orientação Educacional deve ser dialógico e empático, proporcionando um ambiente de trocas de ideias e com respeito a alteridade. A fala de PC sobre a atuação do orientador é: Seu compromisso é com a formação permanente no que diz respeito a valores, atitudes, emoções e sentimentos, sempre discutindo, analisando e criticando.

As orientadoras citam também o trabalho coletivo que acontece com toda escola e comunidade escolar, pois esse profissional acolhe as famílias, auxiliando-as nas demandas necessárias e contribui com as dificuldades que o corpo docente possa apresentar. O que é demonstrado na fala de PB: Precisamos atender, acolher, mediar, aconselhar, ouvir, planejar, acompanhar educandos, educadores, coordenadores pedagógicos, equipe diretiva, pais e toda comunidade escolar.

Sobre a coletividade da praxe do orientador, a autora Vernes (2011) ainda coloca:

A dimensão pedagógica da orientação educacional tem um papel muito abrangente, envolvendo a mediação entre os educadores e demais protagonistas da escola, buscando valorizar as competências de cada um, numa ação efetiva para a melhoria da qualidade nas escolas. Daí, portanto, a importância de se compreender a práxis do Orientador Educacional (OE), como um agente importante da equipe gestora e democrática, e o seu papel frente ao desenvolvimento de uma aprendizagem significativa para a formação de um cidadão crítico e reflexivo (p. 13).

E, na fala de PC: (O Orientador) Trabalha em parceria com o professor para compreender o comportamento dos alunos e agir de maneira adequada em relação a eles. Ouve, dialoga e dá orientações.

Sobre a evasão, todas evidenciam que essa diversidade na praxe do orientador somada à afetividade de suas ações colabora para um trabalho preventivo em relação à evasão escolar e que, por muitas vezes, as razões que levam um aluno a evadir são alheias a sua própria vontade, como por exemplo necessidade de trabalhar ou demanda excessiva de trabalho dos pais que, consequentemente, não conseguem ser presentes na vida escolar dos filhos. Como por exemplo, na fala de PB: Com relação à evasão escolar o orientador(a) é quem liga para alunos e responsáveis, marca entrevista, chama para conversar e convencer que o certo é que o aluno deve estar na escola. Já PA diz: Acredito que a evasão é uma questão de múltipla complexidade, muitas podem ser suas causas, a negligência, drogadição, pobreza extrema, situações de abuso e violência, dificuldades de aprendizagem não acompanhadas, distância da escola e da residência, meios de transporte precários, bullying, uso de metodologias inadequadas por parte dos 
professores, equívocos na avaliação, problemas de relacionamento, enfim, a lista é longa [...] Ao desenvolver essas ações (de caráter afetivo) em sua prática estamos de modo preventivo combatendo à evasão escolar, pois na medida em que o aluno se sente seguro e acolhido na escola ele quer permanecer nela. [...] Me esforço para parar tudo e ouvir o aluno ou o familiar que entra em contato, pois as vezes alguns minutos de atenção bem direcionada são capazes de fazer a diferença e impedir que se perca o aluno.

Já PD se posiciona em relação a evasão da seguinte maneira: (A evasão) Muito sério e sem uma perspectiva boa na verdade, porque é uma ferida muito grande dentro da educação, a evasão escolar. Devido ao desemprego, antes não existia bem um diagnóstico, nós não sabíamos bem porque os alunos evadiam e aí, eu particularmente, comecei a prestar mais atenção no que leva um aluno a desistir. Em primeiro lugar, com toda a certeza, é o cansaço de uma jornada de trabalho [...] depois que eles veem o dinheiro, diante de toda essa dificuldade, os estudos ficam para trás e aí é que eu penso, e tenho certeza disso, que entra o papel do orientador.

Em relação às causas que elevam os índices da evasão escolar, Faria e Moura (2015) nos trazem que aspectos como a pressão que o trabalho exerce sobre as condições dos estudantes trabalhadores, o que implica em limitações para conciliar trabalho, escola e família, repercutem na desistência escolar.

Ao encontro disso, Anuto (2013) acrescenta que a família é apontada como um dos principais determinantes do fracasso escolar da criança, seja pelas suas condições de vida, ou por não acompanhar o aluno em suas atividades escolares.

\subsubsection{Subcategoria: Período posterior ao início da pandemia}

Em relação às mudanças sofridas na rotina de trabalho desses profissionais a partir do início da pandemia pelo COVID-19, também houve o consenso de que a mudança foi total no trabalho do orientador. Todas relatam a importância da presença desse profissional junto aos alunos e da necessidade de adaptação ao mundo virtual para manter esse contato. Sobre isso PB coloca: Nosso trabalho é essencialmente presença, contato, interação com as turmas e individualmente com os alunos e com todos profissionais da escola, assim como com a comunidade escolar. Isto obviamente foi abortado em defesa da vida. PC complementa evidenciando as mudanças sofridas: Os profissionais do SOE, que já faziam o acompanhamento do aluno presencialmente na escola, agora continuam o trabalho por e-mail e telefone, principalmente o whatsapp, buscando atender 
e interagir com as famílias, e particularmente, com os alunos, quando necessário [...] o orientador educacional também se faz presente até nas vídeo conferências, apoiando os responsáveis, os estudantes e os professores na adaptação à nova rotina de atividades on-line. [...] Neste período é de suma importância no estreitamento e relacionamento e o que fizemos foi aproximar-se de nossos alunos, abrimos mais canais de comunicação e que compreendemos o momento das dificuldades, entendendo o que os alunos (ou responsáveis estão sentindo). PD ainda complementa: Mudar mudou tudo, inclusive na minha rotina pessoal [...] eu como orientadora da escola, no início do ano vou conhecer as turmas, eu me apresento, digo que sou aquela que vai chorar junto com eles, é assim, essa é a minha maneira, cada um tem a sua [...] Então mudou tudo, eu trabalho em casa, não tenho contato com eles, o que me frustra muito [...] Então o que que eи fiz, еи uso o meu telefone particular, meu celular [...]. Sobre esse uso de recursos particulares PA nos traz: Tudo mudou, nada mais acontece como antes, os processos permanecem, mas as questões relativas ao tempo e ao espaço foram alteradas. [...] Não há mais limites claros entre o tempo e o espaço, a simultaneidade torna-se um novo elemento da rotina de trabalho.

Sobre os impactos causados pela pandemia na rotina escolar, também abordados acima pelas orientadoras participantes da pesquisa, a autora Elenice Kirchner (2020), na obra "Desafios na Educação em tempos de pandemia", contribui com seu artigo "Vivenciando os desafios da educação em tempos de pandemia":

\begin{abstract}
A pandemia nos colocou frente ao desafio de pensar a escola, nos retirando a sala de aula, o ambiente que sempre foi o lugar de estabelecer os vínculos principais de mediações de conhecimento. A função docente desempenhada dentro desse lugar, onde professores, alunos e toda comunidade escolar se habituaram, já não é o espaço delimitado para essa função. Com o movimento de uma sala de aula é marcado por uma rotina intensa de afazeres, o tempo de pensar sobre outras formas de ser e fazer a aula, acaba sendo redimensionado para outros espaços de formação. Sempre falamos na transformação da escola, que precisamos repensar novos modelos, eis que a pandemia nos obrigou a mudar (p. 46).
\end{abstract}

Na mesma obra referida no parágrafo anterior, o autor Fernando de Lima (2020), em seu artigo "Quando as coisas acontecem antes de acontecer: Educação em um cenário complicado" refere-se ao fato de que as salas de aula são marcadas por aglomerações mais ou menos organizadas, independentemente dos formatos ou contextos, e a partir da suspensão de aulas presenciais todo o planejamento anteriormente precisou ser reformulado. Fato que é comprovado na prática através das falas das orientadoras mostradas anteriormente. 


\subsubsection{Categoria 2: Principais desafios enfrentados pelo OE para o combate à evasão}

Nesta categoria, também definida a priori, procuramos elencar os principais desafios que os Orientadores Educacionais enfrentam no combate à evasão. Para uma compreensão melhor dos desafios prévios à pandemia e também dos durante a pandemia, subdividiu-se em duas subcategorias.

\subsubsection{Subcategoria: Período anterior à pandemia}

Aqui percebemos dois eixos principais nas respostas. Os sujeitos apontam uma questão bem pontual, que é a falta de êxito no contato com as famílias e estudantes, devido a ficha cadastral estar errada ou desatualizada e também, questões relacionadas às dificuldades financeiras enfrentadas pelos estudantes.

Sobre o primeiro eixo citado PA coloca: Olha pode parecer simples demais o que vou te dizer, mas o maior dos entraves está relacionado ao acesso às famílias, principalmente na atualização cadastral, são inúmeras mudanças de número de telefone e isso dificulta e impede o contato com as famílias. PB ainda complementa: Simplesmente parece que os números de contato não existem, ou não podem atender

Já sobre o segundo eixo, podemos observar a informação trazida por PB: A maior dificuldade é lutar contra a necessidade mais básica, a necessidade de sobrevivência. Os pais, geralmente a mãe, sai para trabalhar e deixa os filhos sozinhos, uns cuidando dos outros, adolescentes grávidas, jovens que com 14 ou 15 anos precisam trabalhar para ajudar em casa [...]. Sobre os contatos feitos pela orientação, PB ainda acrescenta: de resposta geralmente recebemos que o mais importante é colocar comida na mesa. Ainda sobre as necessidades financeiras enfrentadas pelas famílias, PD acrescenta: Então tu percebes que os pais estão em uma jornada de trabalho muito grande e há um prejuízo também muito grande para o aluno, e não é um descaso, eu não coloco como um descaso, eu coloco como uma necessidade da jornada dos pais ser tão pesada, e os filhos, infelizmente, os pequenos, ficam a ver navios como a gente fala.

Sobre as dificuldades financeiras enfrentadas pelos estudantes, os autores Faria e Moura (2015) refletem:

Nesse sentido, cabe destacar que a escola é criteriosa e exigente no atendimento às normas do sistema escolar, excluindo dela os que não conseguem seguir os padrões, como por exemplo, os estudantes trabalhadores, porque precisam sobreviver, só sendo possível essa sobrevivência por meio do trabalho... (pág. 152) 
Ainda pensando nessas dificuldades vivenciadas pelas famílias, que repercuti na educação dos estudantes, Anuto (2013) coloca que a família é apontada como um dos principais determinantes do fracasso escolar da criança, seja pelas suas condições de vida, ou por não acompanhar o aluno em suas atividades escolares.

\subsubsection{Subcategoria: Período posterior ao início da pandemia}

De certa forma, podemos perceber que as dificuldades já existentes se mantiveram, sendo acrescidas de novas, como por exemplo o sentimento de pânico causado pelo temor proveniente da pandemia. Sobre isso PA coloca: Esse desafio segue na pandemia, além do que não temos como especificar com certeza o que é evasão e o que é prevenção neste período, pois o discurso da prevenção pode servir para esconder a negligência. E PB complementa com: Neste momento de pandemia lutamos também com o estado de medo de uns e de outros com o desinteresse pelas atividades oferecidas pela escola pois os estudantes achavam que logo em seguida a situação iria se normalizar e o sistema voltaria a ser presencial.

Surpreendentemente, destacando-se das demais colegas, PA é a única profissional que aponta investir em visitas presenciais, ainda que estejamos em pandemia, para vencer a dificuldade, apontada por todas, em relação aos cadastros desatualizados. Sobre isso, a mesma afirma: Agora na pandemia, por incrível que pareça, fui obrigada a investir nas visitas, pois não havia outra forma de atualizar os cadastros, até porque a orientação que temos é que não podemos responsabilizar as famílias junto aos órgãos competentes porque elas teriam o direito de não mandar os filhos para a escola neste momento. Então algumas situações para serem averiguadas apenas indo nas casas. E foi o que fiz."

Sobre as dificuldades financeiras, essas também sofreram acréscimos oriundos da pandemia, pois as famílias que já tinham seus recursos limitados, acabam tendo mais dificuldades em se adaptar às alterações necessárias para manutenção das aulas que, em sua maioria, estão ocorrendo de forma remota através de recursos tecnológicos. Sobre isso, PD nos traz: o que eu mais ouvi foi: professora a gente não tem dinheiro para comprar um celular, ah mas o seu filho tem celular, sim, mas o celular não comporta para abrir os links da plataforma, dá quinze, dez minutos de aula e deu, ou o computador é velho, no meu caso também, ou, professora não tem como, nós dois estamos desempregados, estamos sendo beneficiados pela bolça emergencial então não tem como pensar em celular e computador, é lógico que não, outros moram tão longe, que não passa o cabo da internet e a móvel não comporta, não consegue, a pessoa não vai gastar do 
seu dinheiro, não tem como estar abastecendo a internet e agora surgiu a do estado que é péssima, não é boa, ela é péssima, é de graça e é péssima.

Então em relação à dificuldade financeira vivida pelos alunos, a qual, podemos dizer assim, foi intensificada pela pandemia, a autora Vernes (2011) salienta o fato do acesso à internet via celular, apesar de ser disponível, ainda ser um recurso caro, fato que dificulta a adaptação e acompanhamento das aulas por parte dos estudantes nesse momento de pandemia e que pode se tornar uma dificuldade para o orientador educacional para manter esse aluno motivado a seguir com os estudos.

\subsubsection{Categoria 3: Uso das tecnologias por parte do $\mathrm{OE}$}

Nesta categoria objetivamos compreender como os Orientadores Educacionais utilizam as tecnologias. Para um melhor entendimento, foram construídas duas subcategorias, uma da prática anterior à pandemia e outra durante a pandemia.

\subsubsection{Subcategoria: Período anterior à pandemia}

Buscamos conhecer como era feito o uso das tecnologias por essas profissionais previamente à pandemia. De certo modo, observou-se que o uso já acontecia, porém, em sua maioria, como mero reprodutor de práticas convencionais. Percebemos isso através da fala de PA: Confesso que antes da pandemia usava muito o telefone e o whatsapp para contato com os estudantes e as famílias, e o computador como ferramenta de trabalho. PD chega a comentar que: Eu particularmente não sou das tecnologias, acho que é por causa da antiguidade, mas eu acho muito importante, mas não utilizo, por isso que não consigo te falar sobre isso.

Sobre essa pouca funcionalidade dada ao uso das tecnologias por parte dos Orientadores Educacionais em sua rotina de trabalho, a autora Vernes (2011) já nos evidenciava o fato de que ao se inserir as tecnologias no cotidiano escolar, poderia haver uma certa resistência por parte do docente, que por sua vez, dariam importância a esse recurso somente se o mesmo facilitasse o alcance de seus objetivos educacionais.

\subsubsection{Subcategoria: Período posterior ao início da pandemia}

Já com o início da pandemia, podemos perceber que a maioria, mesmo se mostrando um tanto que resistente em relação ao uso das tecnologias, concorda que esse período pandêmico potencializou a importância e a necessidade de inserção dos recursos tecnológicos em sua praxe laboral. Aquelas que só usavam telefone e computador, esse último como simples instrumento de 
digitação, hoje se veem utilizando redes sociais, Whatssap e demais aplicativos para contato através de recados e reuniões on-line. Percebemos isso através da fala de PA: Nada se compara ao agora. Agora uso aplicativos, ferramentas, faço reuniões, vídeo chamadas, mando áudios, vídeos, enfim todos os recursos que consigo me apropriar para conseguir dar conta de minhas tarefas. PB ainda acrescenta: Os recursos tecnológicos continuam basicamente os mesmos. Notebook pessoal, smartphone pessoal, impressora pessoal. Utilização de mídias sociais (facebook) e aplicativos (whatsapp e telegram). Mas é claro que com a pandemia o contato com os alunos foi muito intensificado nos aplicativos citados. PA enfoca ainda sobre a necessidade de intervenção dialógica com todos os envolvidos no processo educativo devido à resistência e insegurança no uso das tecnologias nesse novo formato trazido pela pandemia, sobre isso, afirma: É um trabalho de convencimento constante, seja com os adultos, jovens ou com as famílias. Do mesmo modo fez-se necessário trabalhar de perto com os professores para que estes também se sentissem capazes e se adequassem as novas formas de interação do processo remoto. $\mathrm{E}$ finalizando esse tópico, PC comenta como o orientador consegue se fazer presente e contribuir na intervenção aludida por PA, Após o início das atividades através das aulas na plataforma google classrroom e também do tira dúvidas no meet [...] o orientador educacional também se faz. presente até nas videoconferências, apoiando os responsáveis, os estudantes e os professores na adaptação à nova rotina de atividades on-line.

Corbellini (2012) acrescenta:

Muito se debate sobre o uso das tecnologias na área da educação. Um dos pontos é como estas podem acrescentar à área, modificando concepções que se encontram em prática há muito tempo. Apontamos que as tecnologias contribuem, servindo de subsídios para a educação, como meios de interações, acesso a diversidade de saberes, instantaneidade dos mesmos, acesso as pesquisas, redes de colaboração e outros. Ou seja, elas podem ser importantes ferramentas auxiliares para incrementar o processo do aprender (p. 3).

Vernes (2011) também comenta sobre o uso das tecnologias por parte da educação, citando em especial a figura do orientador educacional ao afirmar que ele pode ser elo para a integração desse uso à novas metodologias, como por exemplo, possibilitar o acesso a diversas fontes de informação que podem ser encontradas na internet. 


\subsubsection{Categoria 4: Expectativas para o período pós pandemia}

Nessa categoria visa-se verificar as expectativas que esses profissionais têm em relação ao período pós-pandêmico. As expectativas em relação ao período pós pandemia e, consequentemente, o retorno das aulas presenciais, divide opiniões, enquanto PA preocupa-se com o retorno colocando que: Acredito que o maior desafio vai ser encontrar estratégias para garantir a permanência de todos, como nossas escolas não possuem os recursos de infraestrutura ideais para garantir a segurança de todos a nível sanitário, creio que haverá ainda muita insegurança sobre retornar ou não. Não teremos como forçar as pessoas a retornarem. E tememos que as normas de contingenciamento possam dificultar mais a relação entre todos os membros da comunidade escolar, PB tem um olhar mais otimista acreditando que: Sinceramente acredito que estaremos com tanta saudade de nossa convivência que estes problemas vão diminuir. As aulas e as atividades escolares devem ser mais atrativas para os estudantes. Enquanto isso, PD evidencia que ainda nem consegue vislumbrar um momento de retorno: Nós ainda não conseguimos pensar sobre isso porque é muito difícil a gente estabelecer alguma coisa diante de alguma coisa que a gente não acredita, na verdade nós não acreditamos no retorno e não queremos o retorno também, em função da escola pública, principalmente a escola estadual que está sucateada e não existem pessoas para nos ajudarem e colaborarem, nossa escola tem quase mil alunos, no ano passado eram mil alunos, esse ano com toda certeza, e tem uma servente, uma funcionária, como que a pessoa vai limpar tudo isso, como que tu vai fazer aquele protocolo de higienização, não existe, é uma coisa impossível.

Corbellini (2020) acrescenta:

[...] precisamos auxiliar aos nossos estudantes a adquirirem condições de compreensão do mundo, das relações e de lidar com o que está ao seu redor. A grande aprendizagem desse momento, pode ser a potencialidade dessas competências [BNCC] o que irá ajudá-los a desenvolver a sua autonomia, a criticidade, a criatividade e a cooperação. Essas competências irão possibilitar para que se tenham melhores condições de responder aos novos problemas que se apresentarem (p. 67).

Ao encontro do que nos traz Corbellini, o autor Nestor Rambo (2020), em seu artigo "A educação em rede em época de pandemia e pós-pandemia: por uma vida mais solidária e de acolhimento, para as epidemias e crises se repetirem menos", nos traz: 
A aprendizagem é um processo e como tal de nada adiantará querer retomar todo o conteúdo não trabalhado em muitas horas, para compensar os dias perdidos presencialmente na Unidade Escolar. Ao retornarmos da pandemia do Covid-19, será essencial focarmos nas competências, habilidades e conceitos científicos essenciais. Não poderemos estar presos demais aos conteúdos programáticos. Na reorganização do calendário escolar e do currículo escolar a criatividade e a flexibilidade são vitais para todos se inserirem bem e se contextualizarem na retomada dos trabalhos, sem sobrecarregarmos demais os alunos com conteúdos, como tijolos, que não preparam para o trabalho e cidadania (p. 118).

Então, podemos observar a importância do papel do $\mathrm{OE}$ ir além das questões de aprendizagens de conteúdos e, procurar estar atento aos movimentos do mundo, do que nos cerca, das implicações de cada fato em nossas vidas e do quanto é fundamental de que atue de forma solidária e em prol da construção de um sujeito cidadão.

\section{CONSIDERAÇÕES FINAIS}

A partir dos estudos realizados durante a elaboração desse trabalho foi possível percebermos que evasão é um problema sério e bastante antigo, podemos dizer que acompanha a educação desde seus primórdios. Várias são as razões que levam um aluno a evadir, quando o aluno já é adulto, muitas vezes o acesso da carga de trabalho o desmotiva a continuar os estudos, ou simplesmente a incompatibilidade na conciliação de ambos, nesse caso, a necessidade de sobrevivência e manutenção de recursos básicos sempre vence. No caso de alunos mais novos, a quantidade de razões aumenta ainda mais, há casos em que os estudantes não recebem apoio e incentivo necessário por parte dos familiares, variando desde casos mais simples como um familiar que tem dificuldades em cumprir os horários da escola, até mesmo casos que envolvam drogas e abandono familiar.

Com o início da pandemia, a situação referente à evasão escolar só aumentou, pois somouse a todas as razões já existentes uma série de outras questões trazidas pelo isolamento social. Além do estado de pânico instaurado pela pandemia, pelo fato do desconhecido, do medo da contaminação pelo COVID-19, houve toda uma readaptação das escolas na tentativa de manter a educação da melhor forma possível para o momento; só que junto com as adaptações, vêm as dificuldades enfrentadas pelas famílias, como falta de recursos tecnológicos, falta de acesso à internet, falta de espaço apropriado dentro de seus lares para acesso de forma adequada por parte dos alunos, até mesmo falta de habilidades para com a tecnologia, além de como já foi citado, a sensação de insegurança e incerteza causadas pelo novo. 
E é nesse momento de enfrentamento que a figura do orientador escolar se torna ainda mais essencial no combate à evasão. $\mathrm{O}$ trabalho do orientador é solidificado através da empatia, afeto e acolhida ao estudante; muitas vezes esse profissional pode não ter a solução para os problemas enfrentados pelo aluno, mas só o fato de ter um aconselhamento e um atendimento sem julgamentos já promove a esse discente o incentivo necessário e estimulo crucial para prosseguir com os estudos, possibilitando-o a entender a necessidade de sua permanência na escola. Confirmando isso, RAMBO (2020) nos destaca a importância e necessidade da solidariedade e acolhimento para que a evasão escolar não seja ainda maior, adjetivos que pudemos perceber que compõe o perfil dos nossos orientadores.

E como durante a pandemia, houve o isolamento social e o contato presencial foi interrompido, quase que na sua totalidade, as tecnologias vêm para suprir e proporcionar aos envolvidos na educação, que pudessem ultrapassar as barreiras da distância física. Podemos dizer que, de certo modo, esse foi um aspecto positivo causado pela pandemia, afinal, fez com que todos os envolvidos resinificassem o uso de recursos tecnológicos em seu cotidiano laboral. A tecnologia é um fator presente na atualidade e principalmente na vida dos jovens, então essa necessidade de adequação fez com que os profissionais da escola se adaptassem e se apropriassem do uso da tecnologia. Em relação a ela, através da sua utilização, Vernes (2011, pág. 14) nos aponta que o orientador pode ser o elo necessário para integração de novas metodologias. Porém, mesmo com todos os pontos positivos em relação ao uso das tecnologias, não podemos desconsiderar que para tal, houve demasiada exposição de contas virtuais privadas dos profissionais para atender a essa demanda, não somente o fato da exposição dessas contas, como também a utilização de seus aparelhos pessoais em prol do trabalho, muitas vezes até mesmo, sem uma formação adequada para tal.

Sobre o período pós pandemia e, consequentemente, o retorno das aulas presenciais, temos, por enquanto, somente expectativas, visto que ainda estamos em estado pandêmico. Essas, por sua vez, variam de acordo com a percepção de cada um. Mas o que não podemos negar é a importância da atuação do orientador na vida de seus estudantes, seja virtual ou presencial, a figura desse profissional é de extrema importância no combate à evasão escolar, bem como no pleno desenvolvimento de seus estudantes. Ainda em relação a esse retorno, podemos considerar que a tecnologia ganhou um espaço que não abre precedentes para retrocessos, sua utilização por parte de todos, até mesmo dos até então mais resistentes, galgou um novo marco para a educação, que 
poderá até tentar voltar ao modelo antigo, mas jamais ignorar a presença e facilitações que essas adaptações forçadas pela pandemia trouxeram à educação.

Como uma possibilidade de aprofundamento do assunto, para quem se interessar pelo tema, fica a sugestão de uma possível observação em relação à utilização dos recursos tecnológicos por parte de todos os envolvidos no contexto escolar, uma vez que, durante a pandemia, a tecnologia ganhou a visibilidade de todos os sujeitos dessa área, de modo que, resistentes ou não, seu uso foi inevitável, imaginando-se que o retrocesso ao modelo de utilização anterior à pandemia é inimaginável.

\section{REFERÊNCIAS}

ANUTO, Thaína Francis. Evasão escolar no ensino médio: Possíveis inferências para mudar esse cenário. Monografia (Especialização em Educação: Métodos e Técnicas de Ensino). Universidade Tecnológica Federal do Paraná, Medianeira, 2013.

BARDIN, Laurence. Análise de Conteúdo. Tradução Luís Antero Reto e Augusto Pinheiro. São Paulo: Edições 70, 2011.

BRASIL. Lei Federal No 8.069, de 13 de julho de 1990. Dispõe sobre o Estatuto da Criança e do Adolescente e dá outras providências. Disponível em: <http://www.planalto.gov.br/ccivil_03/leis/18069.htm>. Acesso em: 21 de fev. 2021.

CORBELLINI, S. A construção da cidadania via cooperação na educação a distância. SEaD, Universidade Federal de São Carlos, 2012.

CORBELLINI, S. BNCC: Nos trilhos do trem. Revista ENSIN@ UFMS, Três Lagoas/MS, v. 1, n. 5, p. 111-122, Dezembro 2020.

DAVID, Ricardo Santos. O orientador educacional e a escola: a criação de espaços de participação social e exercício da cidadania. Revisa Labor, Fortaleza/CE, jul/dez 2017, Vol. 01, $\mathrm{n}^{\circ} 18, \mathrm{p} .104-117$.

DORE, R.; LÜSCHER, A. Z. Permanência e evasão na educação técnica de nível médio em Minas Gerais. Cadernos de Pesquisa, v. 41, n. 144, p. 770-89, dez. 2011. http://doi.org/10.1590/S0100-15742011000300007

FARIA, D. S. A., MOURA, D. H. Desistência e permanência de estudantes de ensino médio do proeja. HOLOS, 2015, ano 31, Vol. 4.

GRINSPUN, Mirian P. S. Z. A prática dos orientadores educacionais. São Paulo: Cortez, 1994. 
KIRCHNER, Elenice. Vivenciando os desafios da educação em tempos de pandemia. Desafios da educação em tempos de pandemia / organizadores: Janete Palú, Jenerton Arlan Schütz, Leandro Mayer. - Cruz Alta: Ilustração, 2020. 324 p. ; 21 cm

KUPFER, Maria Cristina. Freud e a educação. O mestre do Impossível. São Paulo: Scipione, 1989.

LEMOS, André. Cibertultura como território recombinante. São Paulo ABCiber - Itaú Cultural - CAPES Dezembro de 2009

LIMA, Fernando. Quando as coisas acontecem antes de acontecer: educação em um cenário complicado. Desafios da educação em tempos de pandemia / organizadores: Janete Palú, Jenerton Arlan Schütz, Leandro Mayer. - Cruz Alta: Ilustração, 2020. 324 p. ; 21 cm

LOPES, Daniel de Queiroz, E VALENTINI, Carla Beatris (2012). Mídias locativas e realidade mixada: a produção de sentidos sobre o digital-virtual a partir da cartografia com suporte das tecnologias digitais. Educação Unisinos. Volume 16, número 3, setembro • dezembro 2012.

LORENZET, D.; ZITKOSKI, J. J. Contribuições pedagógicas em institutos federais: o supervisor escolar, o orientador e o pedagogo técnico-administrativo. Educação, Porto Alegre, v. 40, n 3 , p. 459-468, set/dez. 2017.

LÜCK, H. Gestão Escolar e a Formação de Gestores. Brasília: Ed. Azeredo, 2000.

LÜCK, H. Ação Integrada: Administração, Supervisão e Orientação Educacional. 19ª Ed. Petrópolis: Vozes, 2002.

NADAI, Ivan; SANTOS, Franklin. A evasão escolar e o abandono escolar em São Mateus/ES e a implementação do programa Escola Viva. V CONEDU Congresso Nacional Educação. Olinda/PE.

NASCIMENTO, Anderson; GASQUE, Kelley. Novas Tecnologias, a busca e o uso de informação no Ensino Médio. Inf. \& Soc.:Est., João Pessoa, v.27, n.3, p. 205-218, set./dez. 2017

NOAL, Ingrid Kork. Contextualização Do Serviço De Orientação Educacional Na Escola: Trajetórias, Expectativas E Desafios. Prospectiva - Revista De Orientação Educacional, Associação Dos Orientadores Educacionais Do Rio Grande Do Sul, Porto Alegre, v. 3, n. 28, p. 14-17, 2004.

PARO, Victor Henrique. Administração escolar: Introdução crítica. São Paulo: Cortez, 1996.

PASCOAL, M.; HONORATO, E. C.; ALBUQUERQUE, F. A. de. O orientador educacional no Brasil. Educ. Ver. [online], nº 47, p. 1010120, 2008.

PIAGET, J. Sobre a pedagogia. Textos inéditos. São Paulo: Caso do Psicólogo, 1998. 
RAMBO, Nestor. A educação em rede em época de pandemia e pós-pandemia: por uma vida mais solidária e de acolhimento, para as epidemias e crises se repetirem menos. Desafios da educação em tempos de pandemia / organizadores: Janete Palú, Jenerton Arlan Schütz, Leandro Mayer. - Cruz Alta: Ilustração, 2020. 324 p. ; 21 cm

RUMBERGER, R. W. Introduction. In: DROPPING out: why students drop out of high school and what can be done about it. Cambridge, Mass: Harvard University Press, 2011. p. 1-19.

SALES, P. E.; CASTRO, T. L.; DORE, R. Educação Profissional e evasão escolar: estudo e resultado parcial de pesquisa sobre a Rede Federal de Educação Profissional e Tecnológica de Minas Gerais. In: Colóquio Internacional sobre Educação Profissional e Evasão Escolar. Belo Horizonte: Rimepes, 2013.

SILVA, Elenilda; SILVA, Alexandre. Orientação Educacional: Desafios da contemporaneidade. V ENID Encontro de iniciação à docência da UEPB. Universidade Federal de Campina Grande - UFCG/CDSA

SILVA, Raimundo Filho; ARAUJO, Ronaldo. Evasão e abandono escolar na educação básica no Brasil: fatores, causas e possíveis consequências. Educação Por Escrito, Porto Alegre, v. 8, n. 1, p. 35-48, jan.-jun. 2017

VERNES, Cassiane. A orientação educacional mediada pela tecnologia. Disponível em: https://lume.ufrgs.br/handle/10183/79668 Acesso em: 21, fev. 2021. 